Cerebrovascular Disease Vol 1/Number 1 of Neurologic Clinics. Edited by HJM Barnett. (Pp 358; \$18.00.) London: WB Saunders Co, 1983.

Dr Barnett in his introduction to this new venture by the WB Saunders Company confesses that there are too many monographs and series for the average reader to encompass. Nonetheless this is an attractive volume and the subsequent issues which are going to be concerned with headache, multiple sclerosis and neuroophthalmology can only be welcome if they maintain the standard of this first issue. There are some twenty contributions. Some are frankly clinical, such as those on hypertensive encephalopathy, multi-infarct dementia, lacunar strokes, the use of platelet agents and anticoagulants and risk factors. Others are more concerned with pathophysiology, such as Hass's interesting contribution on the cerebral ischaemic cascade and contributions on pathogenesis of transient ischaemic attacks and pharmacological protection against brain damage. Another group of articles is concerned with the investigational techniques including non-invasive methods, digital subtraction angiography, positron tomography and nuclear magnetic resonance. Some rarities are covered, such as fibromuscular dysplasia and dissections of cervical arteries. Surgical interests are covered by chapters on carotid endarterectomy and on saccular aneurysms.

The standard is high throughout with many famous people in the field writing on their own particular subjects. The illustrations are somewhat disappointing, particularly in such situations as nuclear magnetic resonance where the whole point of the aritcle is to demonstrate the improved ability to demonstrate ischaemic lesions with this new technique. Clinicians interested in stroke will find this a valuable book. I particularly found JP Mohr's review on lacunar stroke helpful. I can only hope that the restricted library budget will allow this to be on the neurological shelf.

MJG HARRISON

\section{Electroencephalography in Drug} Research. Edited by Werner M Herrmann. (Pp 608; £50.00) London: Butterworths, 1983.

This weighty tome, the proceedings of a 1980 Berlin Symposium, is well produced and liberally illustrated with figures and there are many tables of data. The con- tributors are well known, particularly in the field of the effect of psychotropic drugs on the EEG. Of special value is the preamble in English and German setting out requirements for drug studies, and the closing remarks which indicate the value and limitations of EEG in the field of clinical pharmacology. In spite of controversy, and the introduction of scanning techniques of various types, the EEG remains one of the tools to study, for example in relation to vigilance. With the newer computerised analysis methods it is certainly not an area to be neglected. For the reader this book serves as a valuable reference on the effects on benzodiazepines and lithium. There is also a chapter describing the effect of yohimbine in the computerised EEG. The contributors present the problems of quantification in all its aspects and though the general reader may not find this a bedside book, there is a vast amount of information and references available here, if at a price.

DF SCOTT

Progress in Neuropathology, Vol 5. Edited by Harry M Simmerman. (Pp 355; \$73.16) New York: Raven Press, 1982.

This is a collection of thirteen chapters on diverse topics of interest to all concerned with the laboratory aspects of diseases of the nervous system. Cytochemistry includes Ingrid Allen's review of hydrolytic enzyme abnormalities and their possible significance in the pathogenesis of multiple sclerosis; a succinct and authoritative discussion of glial fibrillary acidic protein by Eng and DeArmond; and a well documented account by Pearson of the localisation of neurotransmitters (including the neuropeptides) by immunocytochemical methods. Pearson gives details of technical methods for which many readers will be grateful. Other chapters include Hirano's well-illustrated thoughts on the periaxonal space and its pathology; a review of mainly experimental work on measles virus in the CNS (from the NIH laboratories); Wisniewski et al on the electron microscopy of neurofibrillary tangles and amyloid fibrils; a review of the EM of pituitary adenomas (Roy); paraganglioma (Llena) and an exhaustive review by Oehmichen on inflammatory cells in the CNS. I found the chapter by Tateishi et al on Creutzfeldt-Jakob disease in Japan and its experimental transmission to rodents particularly interesting, pointing perhaps to differences between Japanese and Euro- pean forms of the disease. Vogel's little $Z$ chapter is a gem.

The standard of writing, general presentation and illustrations, light and EM, is uniformly high throughout. Strongly $\vec{\varrho}$ recommended.

LW DUCHEN

The Primary Care of Seizure Disorders. By Hugh B McIntyre. (pp 201; £25.00.) Kent: Butterworth Group, 1983.

This short and very readable book can be very highly recommended to all physicians $\overline{\bar{\sigma}}$ and surgeons concerned with the manage- $\vec{D}$ ment of patients with epilepsy. It can also $Q$ be read with profit and understanding by medical students and paramedical person- $\overrightarrow{0}$ nel concerned with people with epilepsy. It is written by several members of the staff of $\overrightarrow{\vec{\omega}}$ the Los Angeles County Harbor General Hospital, UCLA Medical Center, yet its style is remarkably uniform. It is full of relevant and important points and deals with many aspects of the disorder-? epidemiology, clinical features, genetics, $\vec{A}$ EEG, therapy, emergency treatment and $\overrightarrow{-}$ psychiatric problems. A short medico-lega section should be of interest even to doc tors outside the USA. In certain states the physician concerned with the patient $\mathcal{R} \rightarrow$ responsible for reporting the condition $Z$ the appropriate licencing authority, is others this is left to the patient. In some states a hearing is then held at which medis. cal details of the patients are assessed some depth to decide on "driving $\vec{\omega}$ privileges" and these may be restricted to certain hours of the day and the amount of driving permitted in a given period and other specific conditions may be laid down, as opposed to the all or none judgement practised in the UK.

The book contains uptodate references with a surprisingly large number of papers from British and some European journals included.

RS KOCEN 